\title{
Relação entre unidades de conservação e a legislação ambiental brasileira: um estudo de caso na Região Sul
}

Agnes Orzechowski* Veraldo Liesenberg ${ }^{* *}$

\section{Resumo}

As Unidades de Conservação podendo atualmente ser classificadas como de proteção integral ou de uso sustentável, trazem ao Poder Público a possibilidade de categorizar novas áreas de acordo com a finalidade e suas características. O objetivo desse trabalho foi descrever o estado da arte, e discutir sobre as alternativas na categorização de Unidades de Conservação em nível municipal. O Estudo de caso foi desenvolvido no município de Pomerode (Estado de Santa Catarina, Brasil). Observa-se que maiores estudos em relação a viabilidade econômica e social devem ser consideradas, principalmente quando se tratar de uma área que necessite da desapropriação das terras. Na maioria das situações analisadas não há previsão orçamentária para este fim e essas áreas contribuem somente para fins estatísticos e não para a preservação da biodiversidade

Palavras-chave: Unidades de conservação; Plano diretor; Vale do Itajaí.

\footnotetext{
* Faculdade Avantis (biologa.agnes@gmail.com).

** Technische Universität Bergakademie Freiberg (veraldo.liesenberg@student.tu-freiberg.de)
}

Geosul, Florianópolis, v. 24, n. 48, p 131-152, jul./dez. 2009 
ORZECHOWSKI, A.; LIESENBERG, V. Relação entre unidades de...

Relationship between conservation units and the Brazilian environmental law: a case study in Southern Brazil

\begin{abstract}
Conservation Units may be classified by Law either as integral protection or sustainable use nowadays. This law brings to the Government the possibility to categorize new areas according to its characteristics and purposes. The main goal of this study was to describe the state of art of the conservation units in Brazil and to discuss the different possibilities available nowadays to categorize a new conservation unit at district (Municipal) level. The case study selected in this investigation was Pomerode city (Santa Catarina State, Brazil). In this research we conclude that economic and social aspects should be considered with more intenseness in order to verify its implementation viability, mainly when the conservation unit under study shows private areas inside its boundaries. In most of the cases, no financial support is managed to pay compensation and the new conservation unit contribute by the end only for statistic purposes and not for the preservation of the biodiversity as initially expected.
\end{abstract}

Key words: Conservation units; Urban Master plan; Itajaí Valley.

\title{
Introdução
}

A partir da revolução industrial a humanidade vem explorando com maior intensidade e de forma significativa os recursos naturais. Diversos autores têm estimado que essas atividades de exploração já podem ser equiparadas em termos de grandeza e magnitude a de uma força geológica. As estimativas mais recentes apontam que em um intervalo relativamente curto, o ser humano já foi capaz de alterar aproximadamente $40 \%$ da superfície terrestre, suficientes para alterar, por exemplo, o ciclo hidrológico em nível global (VITOUSEK et al., 1997).

A preocupação com as consequências do desenvolvimento e o impacto sobre o meio ambiente fez culminar, em junho de 1972, a Conferência de Estocolmo, sob amparo da Organização das 
Nações Unidas (ONU). Esse evento é considerado o princípio para o alastramento do pensamento ecológico atual, bem como a formação de uma consciência ambiental voltada para os valores da natureza e do habitat dos seres humanos. Os países membros da ONU passaram então, a acompanhar progressivamente essa tendência, dedicando assim, uma maior atenção ao assunto.

Frente a essas mudanças ambientais, vários países têm se preocupado e dedicado a sinalizar medidas que contribuam com a preservação ambiental. Como resultado dessas ações, pode ser citado a Conferência Rio-92 que teve como resultado a formulação da Agenda 21, que tem entre vários objetivos a preservação de florestas e o desenvolvimento sustentável, além da publicação da Declaração de Princípios sobre o Uso das Florestas (Malheiros, 2008).

Uma das formas encontrada pelo Governo Brasileiro para manter e/ou criar novas áreas verdes foi por meio da criação de Unidades de Conservação (UC) e de uma legislação Ambiental (e.g. BRANDON et al., 2005; GODOY, 2006; ABREU e CRISOSTIMO, 2007). O embasamento jurídico para a criação das unidades de conservação se baseia no atual Sistema Nacional de Unidades de Conservação (SNUC) instituída pela Lei 9985/2000 (Brasil, 2000).

Seguindo essa tendência de preservação e lembrando que a Agenda 21 está presente nas diferentes esferas governamentais é natural que com o tempo os municípios também venham a criar UC. Mas além da criação de novas UC é indispensável a elaboração de um plano de manejo, bem como assegurar mecanismos que viabilizem a sua efetiva implantação e ainda que possibilitem implementar os objetivos propostos para a área em questão.

Um plano de manejo elaborado com a efetiva participação da população local facilita o trabalho de preservação e conservação uma vez que as UC são de Poder Público, mas conforme o artigo 225 da Constituição Federal (Brasil, 1988) é a sociedade a maior interessada num ambiente saudável e na qualidade de vida. 
Diante do exposto o presente artigo têm por objetivos:

(1) descrever o estado da arte a respeito da categorização das UC no Brasil;

(2) discutir sobre alternativas na categorização de UC quando pela implantação em nível municipal;

(3) discutir um estudo de caso no município de Pomerode (SC).

\section{Estado da arte}

\section{Unidades de conservação}

A delimitação de áreas com vistas à preservação de seus atributos naturais evoluiu ao longo da história a partir de suas raízes em atos e práticas das primeiras sociedades humanas (MILLER, 1997). As raízes que se refere o autor podem ser entendidas como as necessidades de uso imediato e futuro dos recursos naturais envolvendo água potável, animais, plantas medicinais e outros.

Mas essa preservação não ocorria na perspectiva do bem comum, pois geralmente estava associada aos interesses da realeza e da aristocracia rural. O objetivo principal era a manutenção dos recursos faunísticos e de seus respectivos habitats visando o exercício da caça, ou então a proteção de recursos florestais com fins de uso imediato ou futuro (VALLEJO, 2002).

Segundo Medeiros (2006) desde o século XV, vários Estados europeus intervinham diretamente na proteção, no controle e no acesso de recursos naturais como, por exemplo, a madeira, na época um importante recurso militar e econômico. Somente no século XIX é que se estabeleceu um sistema de áreas naturais protegidas com a criação do Parque Nacional de Yellowstone (EUA). Conforme Brito (2000) este parque caracteriza o início de uma fase em que o Estado passa a ser o maior responsável pelo processo de implantação e gestão territorial das UC.

As bases filosóficas que deram origem ao Parque Nacional de Yellowstone consistiram na época na proteção integral das áreas 
inalteradas pela ação humana. Vallejo (2002) afirma que a perspectiva preservacionista via nos parques nacionais a única forma de salvar área de beleza cênica contra a ação antrópica.

Com o passar do tempo, aos objetivos originais dos sistemas de áreas naturais protegidas foram incorporados novos conceitos que priorizavam a conservação da biodiversidade (BRITO, 2000). Vallejo (2002) destaca que essa nova perspectiva estimulou o uso racional de recursos naturais e o manejo de espécies em áreas naturais protegidas.

Segundo Brito (2000) somente em 1933 com a Convenção para Preservação da Fauna e Flora em seu Estado Natural, realizada em Londres é que se concluiu que:

\begin{abstract}
os Parques Nacionais deveriam ser áreas que fossem controladas pelo poder público, cujos limites não pudessem ser alterados. Onde a caça, abate, captura da fauna e a destruição ou a coleta de flora, fossem proibidos. Onde seriam construídas instalações para auxiliar o público em geral a observar a fauna e flora. Além de proteger e preservar a fauna silvestre e a vegetação nativa, os parques nacionais seriam áreas de preservação de objeto de interesse estético, geológico, pré-histórico, arqueológico e outros interesses científicos.
\end{abstract}

Apesar do conceito de Parque Nacional estabelecido, não houve na época nenhuma consideração com as populações que já habitavam as áreas que se tornavam protegidas. Segundo Brito (2000) as regras impostas aos Parques Nacionais angariaram a antipatia das populações locais para com o conceito de proteção da vida selvagem, pois os recursos naturais estavam sendo protegidos por razões não práticas e sem consideração para com os direitos tradicionais de uso.

A situação da população que já habitava os locais que estavam se tornando Parques Nacionais só foi considerada na $11^{\mathrm{a}}$ Assembléia Geral da União Internacional para a Conservação da Natureza, realizada no Canadá em 1972. A partir dessa Assembléia foram criadas categorias que permitissem o manejo 
sustentado dos recursos e a permanência da população local (BRITO, 2000).

No Brasil, os principais dispositivos de proteção da natureza foram criados no início da década de 30. Dentre eles, o instrumento mais importante foi o Código Florestal (Brasil, 1934). Ele tinha como objetivos principais legitimar a ação dos serviços florestais, regularizar a exploração do recurso madeireiro e estabelecer as bases para sua proteção. Foi com o Código Florestal que se definiram claramente as tipologias de áreas a serem especialmente protegidas em:

(a) Florestas Remanescentes: de domínio público, onde era proibida qualquer atividade contra a flora e a fauna;

(b) Florestas de Rendimento e de modelo: suscetíveis de exploração econômica, classificada atualmente como Florestas Nacionais; e

(c) Florestas Protetoras: as florestas que tivessem finalidade de conservar os regimes das águas, evitar a erosão, fixar dunas, assegurar a salubridade pública, assegurar áreas para a proteção de sítios arqueológicos, e espécimes da fauna.

Seguindo a mesma linha filosófica do Código Florestal de 34 foi sancionado em 1965 o novo Código Florestal (Brasil, 1965). Entretanto, o novo código substituiu as tipologias de classificação por quatro novas entre elas, o Parque Nacional, a Floresta Nacional, as Áreas de Preservação Permanente e a Reserva Legal (MEDEIROS, 2006).

Para garantir que o Código Florestal fosse cumprido foi criado em 1967 o Instituto Brasileiro de Desenvolvimento Florestal (IBDF). Apesar do arcabouço conceitual, e a ação de um órgão fiscalizador, a efetiva aplicação do Código Florestal não se efetivou em termos práticos.

O Brasil sentiu a necessidade de conduzir um projeto político nacional para o meio ambiente, frente a uma série de Conferências Ambientais realizadas na década de 70, criando em 1973, a Secretaria Especial do Meio Ambiente (SEMA). 
Esperava-se que com a criação da SEMA, esta assumisse as funções de gestão das áreas protegidas, mas a secretaria acabou estabelecendo um programa próprio de áreas protegidas (MERCADANTE, 2001). As áreas protegidas criadas pela SEMA foram a Estação Ecológica, a Área de Proteção Ambiental, a Reserva Ecológica, a Área de Relevante Interesse Ecológico e a Reserva Particular do Patrimônio Natural.

Em 1989, SEMA e IBDF foram unidos para formar o Instituto Brasileiro do Meio Ambiente e dos Recursos Naturais Renováveis (IBAMA) que contemplou a responsabilidade da gestão de UC, juntamente com outras funções, a exemplo dos licenciamentos ambientais e de fiscalização. Um aspecto muito importante desse Instituto foi que após uma longa tramitação no legislativo, o Sistema Nacional de Unidades de Conservação (SNUC) fora aprovado em 2000 (Brasil, 2000). A idéia central do SNUC é promover o uso sustentável dos recursos naturais (Artigo $4^{\circ}$; Inciso IV). Para isso, o SNUC congregou as categorias de UC propostas pelo Código Florestal, pela SEMA, e contemplou a Lei 5197/67 que trata da proteção da fauna, abrindo ainda espaço para que novas categorias fossem criadas. Tamanha responsabilidade, fez com que o IBAMA fosse dividido recentemente, criando assim, o Instituto Chico Mendes de Conservação da Biodiversidade, um órgão voltado única e exclusivamente para gerenciamento de UC (Brasil, 2007). O SNUC bem como as categorias por ele utilizadas será discutido no tópico a seguir.

\section{Atuais categorizações de UC}

O SNUC veio consolidar os conceitos de Proteção Integral e de Uso Sustentável que até então eram implícitos. O conceito exposto no SNUC afirma que a Proteção Integral é a manutenção dos ecossistemas livres de alterações causadas por interferência humana, admitido apenas o uso indireto dos seus atributos naturais. $\mathrm{O}$ uso indireto é aquele que não envolve consumo, coleta, dano ou destruição dos recursos naturais. Pertencem a esse 
grupo: a Estação Ecológica (EE); a Reserva Biológica (RB); o Parque Nacional (PN); o Monumento Natural (MN); e o Refúgio da Vida Selvagem (RVS) (Brasil, 2000).

Assim o uso sustentável permite explorar o ambiente de maneira a garantir a perenidade dos recursos ambientais renováveis e dos processos ecológicos, mantendo a biodiversidade e os demais atributos ecológicos, de forma socialmente justa e economicamente viável. Nesse grupo estão presentes: a Área Proteção Ambiental (APA); a Área de Relevante Interesse Ecológico (ARIE); a Floresta Nacional (FN); a Reserva Extrativista (RE); a Reserva da Fauna (RF); a Reserva de Desenvolvimento Sustentável (RDS); e a Reserva do Patrimônio Particular Natural (RPPN) (Brasil, 2000).

Para entender melhor as diferenças entre as diferentes categorias dentro da classificação de Proteção Integral e de Uso Sustentável a Tabela 1 relaciona alguns aspectos que regulamentam a criação, estruturação e funcionamentos das diferentes categorias de proteção propostos pelo SNUC.

De acordo com a síntese apresentada na Tabela 1, observase que a consulta pública é obrigatória para nove das doze categorias do SNUC. Vale salientar que dentre essas, a que pode ser criada por qualquer pessoa física é a RPPN, sendo a mesma isenta de impostos e mantendo o título de posse. Entretanto, um plano de manejo detalhado é exigido em todas as categorias, embora com prazo de cinco anos após a efetivação legal da UC, o que de certa forma é incoerente, já que aspectos prévios de investigação poderiam recomendar outros traçados para a área ou até o enquadramento da UC em questão em uma categoria.

Vale ressaltar que boa parte das UC é criada sem qualquer previsão orçamentária tão menos para a sua posterior regularização fundiária. Há exceções, no entanto, quando estas recebem recursos provenientes de compensações ambientais ou são exigidas por financiamentos internacionais. $\mathrm{O}$ mesmo aspecto se repete com a desapropriação de terras. Uma revisão sobre o assunto mostrou que não há nenhuma menção sobre fontes para 
ORZECHOWSKI, A.; LIESENBERG, V. Relação entre unidades de...

essa atividade e nem o prazo para isso venha a acontecer após a criação de uma UC.

Tabela 1: Estudo comparativo entre os diferentes critérios para a criação, estruturação e funcionalidades das diferentes categorias de proteção propostos pelo SNUC (Brasil, 2000).

\begin{tabular}{|c|c|c|c|c|c|c|c|c|c|c|c|c|}
\hline & \multicolumn{5}{|c|}{ PROTEÇÃO INTEGRAL } & \multicolumn{7}{|c|}{ USO SUSTENTÁVEL } \\
\hline & 峩 & $\tilde{\approx}$ & $\mathrm{Z}$ & $\mathbf{Z}$ & $\sum_{z}^{\infty}$ & $\overleftrightarrow{\frac{1}{4}}$ & 될 & Z & $\stackrel{1}{x}$ & $\approx$ & $\hat{\underline{z}}$ & $\frac{Z}{\underline{\tilde{z}}}$ \\
\hline Consulta Pública & $\mathrm{N}$ & $\mathrm{N}$ & $\mathrm{s}$ & $\mathrm{s}$ & $\mathrm{s}$ & $\mathrm{s}$ & $\mathrm{s}$ & $\mathrm{s}$ & $\mathrm{s}$ & $\mathrm{s}$ & $\mathrm{s}$ & $\mathrm{N}$ \\
\hline Plano de Manejo & $\mathrm{S}$ & $\mathrm{s}$ & $\mathrm{S}$ & $\mathrm{s}$ & $\mathrm{s}$ & $\mathrm{S}$ & $\mathrm{S}$ & S & $\mathrm{S}$ & $\mathrm{S}$ & $\mathrm{S}$ & $\mathrm{s}$ \\
\hline Previsão de Orçamento & $*$ & $*$ & $*$ & $*$ & $*$ & $*$ & $*$ & $*$ & $*$ & $*$ & $*$ & $*$ \\
\hline Desapropriação de terras & $\mathrm{s}$ & $\mathrm{s}$ & $\mathrm{S}$ & $\mathrm{N}$ & $\mathrm{N}$ & $\mathrm{N}$ & $\mathrm{N}$ & $\mathrm{R}$ & $\mathrm{R}$ & $\mathrm{S}$ & $\mathrm{N}$ & $\mathrm{N}$ \\
\hline Zonas de Amortecimento & $\mathrm{s}$ & $\mathrm{S}$ & $\mathrm{S}$ & $\mathrm{s}$ & $\mathrm{S}$ & $\mathrm{N}$ & $\mathrm{s}$ & $\mathrm{S}$ & $\mathrm{S}$ & $\mathrm{s}$ & $\mathrm{S}$ & $\mathrm{N}$ \\
\hline Recuperação Ambiental & $\mathrm{s}$ & $\mathrm{s}$ & $\mathrm{s}$ & $*$ & $*$ & $\mathrm{~s}$ & $\mathrm{~s}$ & $\mathrm{~S}$ & $\mathrm{~s}$ & $\mathrm{~s}$ & $\mathrm{~s}$ & $\mathrm{~s}$ \\
\hline Visitação pública & $\mathrm{E}$ & E & $\mathrm{EL}$ & $\mathrm{L}$ & $\mathrm{L}$ & $\mathrm{L}$ & $*$ & $\mathrm{R}$ & $\mathrm{R}$ & $\mathrm{R}$ & $\mathrm{R}$ & $\mathrm{R}$ \\
\hline Pesquisa Científica & $\mathrm{R}$ & $\mathrm{R}$ & $\mathrm{R}$ & $\mathrm{R}$ & $\mathrm{R}$ & $\mathrm{R}$ & $\mathrm{R}$ & $\mathrm{R}$ & $\mathrm{R}$ & $\mathrm{R}$ & $\mathrm{R}$ & $\mathrm{R}$ \\
\hline
\end{tabular}

Note que: $\mathrm{S}=\mathrm{SIM} ; \mathrm{N}=\mathrm{N} \tilde{\mathrm{AO}}$; R=Restrição - é definido pelo Plano de Manejo; $\mathrm{E}=$ Educação Ambiental; L= Lazer prevista no plano de manejo; * = não menciona.

Legenda: $\quad \mathrm{EE}=$ Estação Ecológica, $\mathrm{RB}=$ Reserva Biológica, $\mathrm{PN}=$ Parque Nacional, $\mathrm{MN}=$ Monumento Natural, RVS $=$ Refúgio da Vida Selvagem, APA = Área de Proteção Ambiental, FN = Floresta Nacional, RE = Reserva Extrativista, RF $=$ Reserva da Fauna, RDS = Reserva de Desenvolvimento Sustentável, RPPN = Reserva Particular do Patrimônio Natural.

Conforme Tabela 1, somente a APA e RPPN não necessitam de zonas de amortecimento, cujo objetivo central é proteger gradualmente os limites de uma determinada UC. Na primeira situação, isso se deve ao fato de que entre os motivos para a concepção de uma APA estavam à intenção de criar um instrumento mais adequado para a proteção do entorno de outras categorias de uso indireto (i.e. proteção integral), bem como criar UC (estas de uso indireto) em áreas aonde houvesse presença de ocupação humana em que a indenização e realocação previstas fossem demoradas ou inviáveis (BRASIL, 1981). 
Em outra análise está a RPPN que em geral constitui-se de áreas menores, para fins preservacionistas muitas vezes particulares, seja para proteção, seja para alguma fonte de renda, já que a administração passa a ser do próprio proprietário do imóvel, ou alguém por ele designado e não o poder público. Prosseguindo com a análise da Tabela 1, no que se referem à alteração para recuperação ambiental dez das doze categorias permitem, desde que seja como medidas que visem à restauração do ecossistema ou manejo de espécies como meio para preservar a diversidade biológica. Apenas duas categorias não mencionam essa possibilidade (MN e RVS). Quanto à pesquisa científica todas as Unidades permitem a pesquisa desde que observados o plano de manejo e ou regulamento próprio.

Em relação à visitação pública encontramos basicamente duas utilizações, uma com a intenção da educação ambiental e outra como forma de lazer (Tabela 1). Das categorias analisadas na Tabela 1 três mencionam a visitação pública com o objetivo de lazer, já o Parque Nacional possibilita através do plano de manejo atividades de educação ambiental e de lazer. Enquanto que na Estação Ecológica e na Reserva Biológica a visitação pública são exclusivamente para a educação ambiental. As demais categorias permitem a visitação, mas com restrições descritas no plano de manejo.

Em relação à definição dos usos e atividades econômicas em bases sustentáveis se destacam a RDS e a RE. Na primeira situação, a população deve residir na área da UC onde poderão explorar componentes do ecossistema e implantar espécies cultiváveis em seu interior, implicitamente é permitida a mineração e a criação de animais de grande porte e caça (WWF Brasil, 2007).

Por outro lado, em áreas de RE não há autorização explícita para substituição da cobertura vegetal por espécies cultiváveis enquanto que a caça, a mineração, e a criação de animais de grande porte não são permitidas. Nessa categoria, poderá haver ou não a residência da população tradicional, mas estes devem 
ORZECHOWSKI, A.; LIESENBERG, V. Relação entre unidades de...

utilizar a área da UC exclusivamente para tal atividade. A demarcação de áreas para proteção integral, por exemplo, é exigida para a RDS.

Em relação à representatividade das diferentes categorias de Unidades de Conservação (UC) federais e estaduais no Brasil, percebe-se a dificuldade de estatísticas oficiais recentes. Uma razão para isso pode estar relacionada com a criação de inúmeras UC nos últimos anos, justificando assim a ausência de dados sobre área (ha ou $\mathrm{km}^{2}$ ) para algumas UC. A Tabela 2 mostra o número e a área das UC de responsabilidade da Federação, dos Estados e particularmente sobre as UC de responsabilidade do Estado de Santa Catarina. Os dados foram baseados em múltiplas fontes de consulta relatados no rodapé da referida tabela.

Segundo os dados apresentados na Tabela 2, as UC de conservação federais respondem em área por $38 \%$ em categorias de proteção integral enquanto que $62 \%$ de uso sustentável. Segundo Brandon e Rylands (2005), entre os biomas, entretanto, ocorrem diferenças substanciais nesse equilíbrio. A proteção integral é mais comum nos biomas Pantanal (100\%) e no Cerrado (69\%), enquanto que as áreas de uso sustentável nos domínios da Mata Atlântica (74\%), Caatinga $(72 \%)$ e regiões costeiras e marinhas (74\%). Somente na Amazônia existe um equilíbrio aproximado entre proteção integral e uso sustentável (aproximadamente $50 \%$ para cada categoria).

Segundo a Tabela 2 observa-se um predomínio das categorias de proteção integral PN (62 unidades) seguidos por EE (32) e RB (29) em UC de responsabilidade da União. Por outro lado, observa-se um número expressivo para a categoria RPPN (462) salientando-se que a menor área encontrada para essa classe foi de 0,6ha. Em área destacam-se a $\mathrm{FN}$ (63) seguida por APA (31) e RE (50). Esses dados confirmam a dificuldade do Estado enquadrar uma determinada UC a uma adequada categoria e classe conforme relatado por Pádua (2002).

Sob a percepção de Brandon e Rylands (2005), os Estados investiram relativamente pouco nas unidades de proteção integral, 
ORZECHOWSKI, A.; LIESENBERG, V. Relação entre unidades de...

e elas constituem somente $16,5 \%$ da área total sob sua tutela. Entretanto, as unidades de conservação de uso sustentável são mais frequentes (302 unidades e uma área de 46.485.786ha) (Tabela 2). Nos Estados a APA destacam-se em número (181) e em área (69\%). Segundos os autores as APAs são mais próximas de um mecanismo para ordenamento do uso da terra que uma área protegida verdadeira, envolvendo zoneamentos que incluem algumas unidades de proteção integral.

Tabela 2: Número e área total das diferentes categorias de Unidades de Conservação (UC) de responsabilidade da União, Estados e particularmente para o Estado de Santa Catarina.

\begin{tabular}{|c|c|c|c|c|c|c|}
\hline \multirow{2}{*}{$\begin{array}{l}\text { UNIDADES DE } \\
\text { CONSERVAÇÃ̃O }\end{array}$} & \multicolumn{2}{|c|}{ FEDERAIS $^{1}$} & \multicolumn{2}{|c|}{ ESTADUAIS $^{2}$} & \multicolumn{2}{|c|}{ SANTA CATARINA $^{3}$} \\
\hline & Número & $\begin{array}{c}\text { Area } \\
\text { (ha) }\end{array}$ & Número & $\begin{array}{c}\text { Area } \\
\text { (ha) }\end{array}$ & Número & $\begin{array}{c}\text { Area } \\
\text { (ha) }\end{array}$ \\
\hline \multicolumn{7}{|c|}{ PROTEÇÃO INTEGRAL } \\
\hline $\mathrm{EE}$ & 32 & 7.203 .379 & 136 & 724.127 & 01 & 4.606 \\
\hline $\mathrm{RB}$ & 29 & 3.740 .545 & 46 & 217.453 & 03 & 14.794 \\
\hline $\mathrm{PN}^{*}$ & 62 & $17.074 .717^{*}$ & 180 & 7.697 .662 & 06 & 97.953 \\
\hline $\mathrm{MN}$ & 0 & 0 & 2 & 32.192 & - & - \\
\hline RVS & 3 & $128.521 *$ & 3 & 102.543 & - & - \\
\hline Subtotal & 126 & $28.147 .162 *$ & 367 & 8.773 .977 & 10 & 117.353 \\
\hline \multicolumn{7}{|c|}{ USO SUSTENTÁVEL } \\
\hline APA & 31 & 8.578 .921 & 181 & 30.711 .192 & - & - \\
\hline ARIE & 17 & 40.881 & 19 & 12.612 & - & - \\
\hline FN & 63 & $16.876 .671,44$ & 58 & 2.515 .950 & - & - \\
\hline $\mathrm{RE}$ & 50 & 8.025 .490 & 28 & 2.880 .921 & - & - \\
\hline RF & 1 & 6.200 & - & - & - & - \\
\hline RDS & - & - & 16 & 10.375 .111 & - & - \\
\hline RPPN & 462 & $447.801,5$ & - & - & & \\
\hline Subtotal & 624 & $44.351 .075,94$ & 302 & 46.485.786 & & \\
\hline TOTAL & 750 & 72.498.237,94 & 669 & 55.269 .763 & 10 & 117.353 \\
\hline
\end{tabular}

(*) Unidades de Conservação com informações não disponíveis.

Em Santa Catarina 06 são os Parques Estaduais existentes totalizando $97.953 \mathrm{Km}^{2}$ o que corresponde a $75 \%$ da área sob responsabilidade do Estado. Ainda na categoria de UC de proteção integral Santa Catarina conta com 03 Reservas Biológicas que 
correspondem a $11 \%$ das UC $\left(14794 \mathrm{Km}^{2}\right)$ e com 01 Estação Ecológica que corresponde a 3,5\% (4606 $\left.\mathrm{Km}^{2}\right)$.(Tabela 2). $\mathrm{Na}$ categoria de uso sustentável Santa Catarina conta com 43 RPPN totalizando $13598,19 \mathrm{Km}^{2}$ que corresponde a $10 \%$ da área preservada.

\section{Estudo de caso: criação de Unidades de Conservação no município de Pomerode-SC}

O município de Pomerode localizado no Vale do Itajaí caracteriza-se por possuir um relevo acidentado, formado por vales estreitos e com encostas íngremes. Essas condições não favoráveis à agricultura favoreceram a preservação de uma expressiva cobertura vegetal, em diferentes estágios sucessionais da Mata Atlântica como observado em outras cidades do Vale do Itajaí (VIBRANS e PELLERIN, 2004). As Figuras 1a e 1b mostram a localização da área de estudo dentro dos contextos nacional e estadual

Considerando que na região há vários mananciais de água e que há uma crescente preocupação com a preservação ambiental, foi proposta através da recente atualização do Plano Diretor Municipal de Pomerode de 1996 a criação de várias UC. Conforme o Estatuto da Cidade (Lei Federal $\left.n^{\circ} 10.251 / 2001\right)$ (Brasil, 2001), o Plano Diretor é obrigatório em todas as cidades com mais de 20 mil habitantes.

Tendo em vista a Resolução $\mathrm{n}^{\mathrm{o}} 15$ que institui a Campanha de Plano Diretor Participativo (Brasil, 2004), definiram-se critérios e metas para o uso e ocupação do solo, formulação de políticas públicas de habitação, mobilidade urbana e saneamento ambiental. Dentro dos critérios e metas estabelecidos para o saneamento ambiental propôs-se a criação de pelo menos cinco unidades de conservação cujas delimitações e definições de categorias ainda estão sujeitas a mudanças e deverão ser definidas por meio de estudos e projetos específicos (Plano Diretor Municipal de Pomerode, 2007). As UC consideradas na proposta até o presente 
momento foram de cinco sem menção clara a respeito de sua categorização.

A Figura 1c mostra a representatividade dos fragmentos florestais mapeados pela Fundação SOS Mata Atlântica (SOS Mata Atlântica, 2000) com a delimitação das possíveis UC. A delimitação das UC foi feita pelos autores em ambiente SIG (Sistemas de Informações Geográficas) baseada nas descrições das propostas anexadas à revisão do Plano Diretor. Como havia muitas dúvidas quanto à delimitação, foram consideradas para a delimitação as sub-bacias hidrográficas do município, já que a delimitação única e exclusiva por curvas de nível como descritas no Plano Diretor acarretariam em expressivas áreas.

Os resultados iniciais mostram que pouco mais de $20 \%$ da área do município de Pomerode (21514ha) será destinada à criação das cinco UC. Das cinco UC propostas pelo Plano Diretor, quatro deles abrangem áreas com importantes remanescentes da Mata Atlântica. As UC Wunderwaldt, Ribeirão Souto e Canudos, segundo a Figura 1c, com pouca ocupação humana e interferência agrícola. O objetivo principal na criação dessas áreas é a preservação da vegetação e dos mananciais hídricos existentes.

A quarta UC trata-se de uma área com características urbanas na área central da cidade (UC Rio do Testo, Figura 1c), com o objetivo de dar início a formação dos parques lineares ao longo do rio, visando simultaneamente a proteção ambiental e a criação de alternativas de lazer e recreação para a população semelhante ao observado na Beira-Rio e Beira-Mar em Blumenau e Florianópolis, respectivamente.

A quinta área trata-se de uma área aonde é realizada atualmente parte da coleta de água do município (UC Pomeranos, Figura 1c) e, portanto, tem como objetivo a proteção e conservação de mananciais. Das cinco áreas de proteção propostas apenas duas são indicadas pelo Departamento de Meio Ambiente do município como sendo de implantação prioritária, a saber, as UC Canudos e Rio do Testo (Figura 1c). 


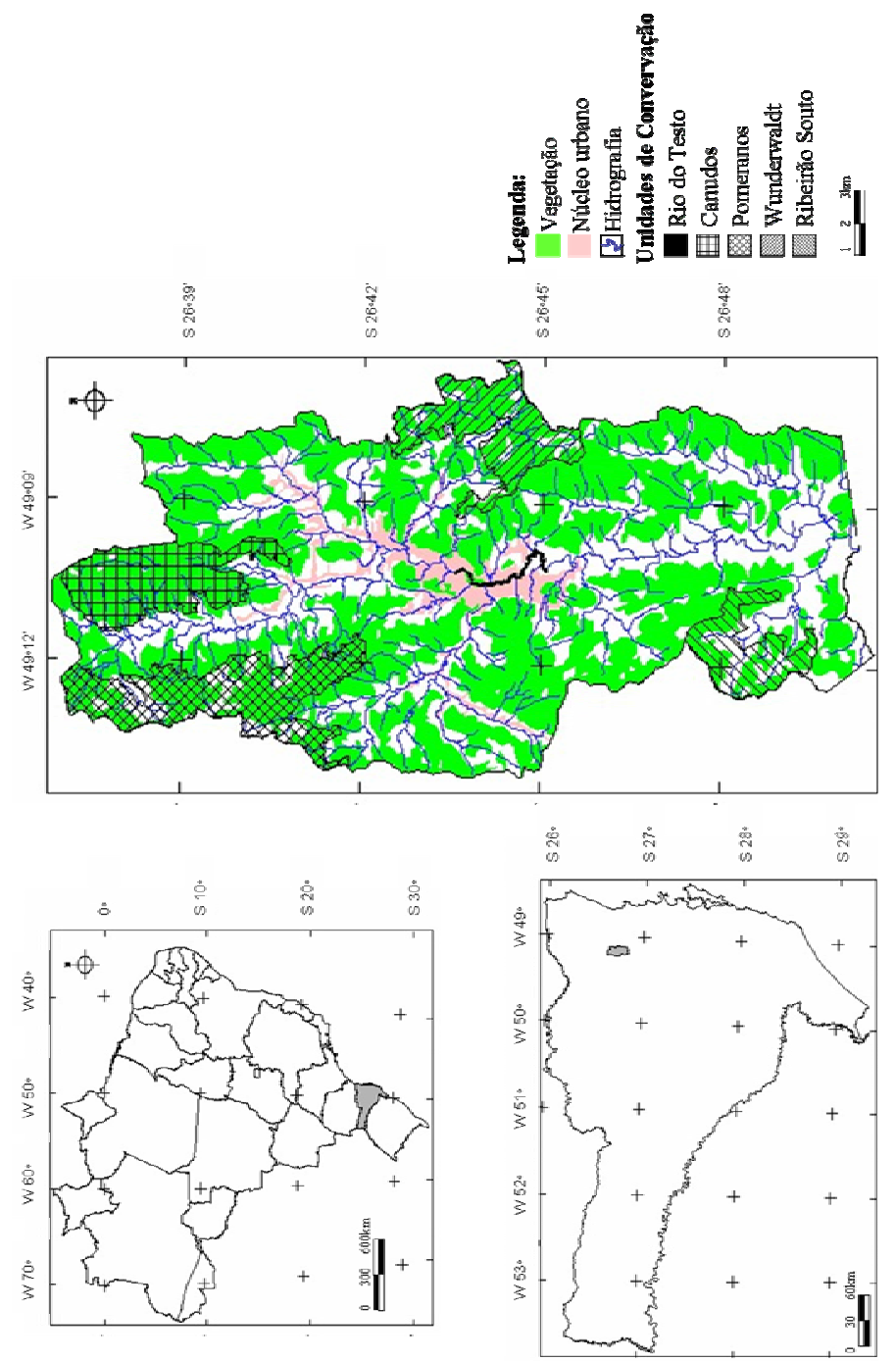

Figura 1: Localização da área de estudo dentro dos contextos: (a) nacional e (b) estadual. (c) Distribuição espacial dos fragmentos florestais com a delimitação das cinco possíveis UC em Pomerode (SC). 
Apesar de não haver menção clara a respeito de sua categorização das UC considera-se importante evitar que todas as áreas sejam enquadradas como Parques Nacionais, na condição municipal, Parque Natural Municipal (PNM). Pois isto despediria uma série de ações apresentadas na Tabela 1, principalmente a questão das desapropriações, que na UC do Rio do Testo seriam aproximadamente 170 propriedades.

Arruda (1999) destaca que um dos problemas enfrentados na criação de uma UC tem sido o custo das desapropriações, inflacionado por manobras jurídicas e contábeis de uma indústria de indenizações. A morosidade do processo aliada à especulação imobiliária tornam a criação de uma UC muito complexa e as vezes questionável.

Por outro lado, Soares (2002) corrobora com Arruda e acrescenta que a situação fundiária de cada UC representa um dos maiores obstáculos à gestão satisfatória das áreas protegidas no Brasil. Uma simples consulta as informações dos PN mostraram que $56 \%$ das unidades não possuem a sua situação fundiária regularizada, 29\% está parcialmente regularizada enquanto que $15 \%$ não dispõem de qualquer informação a respeito.

Um exemplo dessa dificuldade de implantação é o Parque Nacional do Itatiaia (RJ) que apesar de ser o mais antigo existente no Brasil ainda não foi totalmente desapropriado. O PN de São Joaquim, o PN das Araucárias e o PN da Serra do Itajaí, unidades do Estado de SC encontram-se em situação semelhante.

Portanto para evitar que a desapropriação dos terrenos seja um empecilho para a proteção ambiental considera-se apropriado analisar categorias que permitam a permanência da população local. Nesse caso, deve-se ainda considerar o objetivo da área bem como a sua localização.

Nesse sentido o MN, a RPPN, a RE e a APA são unidades por categorias que poderiam atender essa necessidade. Aliada à possibilidade de permanência da população local na área de proteção potencializam-se as atividades desenvolvidas como a 
pesca, a produção de mel, a extração de palmito e madeira, e o turismo rural.

Assim, sugere-se um intenso trabalho de educação ambiental para desmistificar a crença de que sendo criadas áreas de proteção os proprietários perdem domínio sobre a sua propriedade ou que não podem mais utilizá-la. A importância de aspectos sociais e UC são destacadas por Röper (1999) e Castro et al. (2006). Outro aspecto interessante a ser analisado que tanto a RPPN quanto a APA não necessitam da instalação de zonas de amortecimento.

Uma característica atraente de uma APA é que sua criação não implica na necessidade de desapropriação (Tabela 1). Pressupõe-se nessa categoria que a manutenção e/ou recomposição das condições ecológicas da área seria alcançada através de uma série de adequações e restrições ao direito da propriedade.

Outro aspecto relevante nessa categoria é que a reversão (ou seja, o enquadramento de uma categoria de uso direto para outra categoria de uso indireto) é possível. Regionalmente, a experiência mais antiga e de boa repercussão endereça-se à APA Federal de Guaraqueçaba/PR, onde já se consta com um acervo de quase uma década de iniciativas de planejamento e manejo numa parceria entre o governo federal com organizações não governamentais.

Medidas simples de categorização e estudos específicos para cada área podem evitar que UC passam a integrar o rol dos chamados parques de papel, principalmente em municípios onde não se dispõem de bases operacionais para a sua operacionalização. É importante salientar a importância dos mecanismos de fomento criados através do chamado ICMS ecológico, que concede aos municípios detentores de áreas localizadas em UC uma parcela adicional do referido imposto. Pioneiramente introduzido no Paraná, o ICMS ecológico pode ser encontrado em vários outros Estados brasileiros. Em Santa Catarina encontra-se em trâmite o Projeto de Lei Complementar $n^{\circ} 10.9 / 2003$ (Santa Catarina, 2003) que trata sobre o assunto. 


\section{Considerações finais}

O presente trabalho ao analisar o estado da arte da categorização das UC no Brasil e discutir alternativas na categorização de UC quando pela implantação em nível municipal, observou que são necessários estudos para avaliar aspectos econômicos e sociais.

Nos aspectos econômicos destaca-se principalmente a questão da desapropriação de terras, uma vez que a maioria das UC não tem previsão orçamentária para esse fim. Ligada à questão da desapropriação está a questão social, uma vez que a população que tradicionalmente reside na região a ser desapropriada terá de ser deslocada, transferindo um problema social para outras áreas ou centros urbanos.

Constata-se a necessidade do próprio Poder Público na clareza da viabilidade da criação das UC e das possibilidades de classificação de manejo. Conforme Silva (1997) e Tabarelli et al. (2005), as UC podem contribuir para uma boa qualidade ambiental e de vida da população. Mas é fundamental que se adotem políticas públicas apoiadas em um projeto de desenvolvimento sustentado para a cidade, previamente e amplamente debatido com a sociedade, baseado em princípios ecológicos e socialmente justos.

\section{Agradecimentos}

À Sra. Graziela Silva (Faculdade Avantis) pela leitura prévia do manuscrito

À Sra. Márcia Hirota da Fundação SOS Mata Atlântica pela cessão dos dados digitais dos fragmentos florestais.

Á Prefeitura Municipal de Pomerode na pessoa do Sr. Jaime Jensen, secretário da Agricultura e Meio Ambiente do Município pelas informações cedidas para o desenvolvimento dos estudos. 
ORZECHOWSKI, A.; LIESENBERG, V. Relação entre unidades de...

\section{Referências bibliográficas}

ARRUDA, R. Populações tradicionais e a proteção dos recursos naturais em unidades de conservação. Ambiente \& Sociedade (Campinas), n.5, p.79-92, 1999.

BRANDON, K.; FONSECA, G.A.B.; RYLANDS, A.B.; SILVA, J.M.C. Conservação brasileira: Desafios e oportunidades. Megadiversidade (Belo Horizonte), v.1, n.1, p. 07-13, 2005.

BRASIL. Constituição (1988). Constituição da República Federativa do Brasil: promulgada em 5 de outubro de 1988. Organização do texto: Juarez de Oliveira. 4.ed. São Paulo: Saraiva, 1990. 168 p.

BRASIL. Lei $\mathrm{n}^{\circ}$ 4.771, de 15 de Setembro de 1965. Institui o Novo Código Florestal.

BRASIL. Lei 6902, de 27 de abril de 1981. Dispõe sobre a criação de estações ecológicas, áreas de proteção ambiental e dá outras providencias.

BRASIL. Lei n.9.985, de 18 de Julho de 2000. Institui o Sistema Nacional de Unidades de Conservação da Natureza - SNUC. Estabelece critérios e normas para a criação, implantação e gestão das unidades de conservação.

BRASIL. Lei 10.257 de 10 de julho de 2001. Estabelece normas de ordem pública e interesse social que regulam o uso da propriedade urbana em prol do bem coletivo, da segurança e do bem-estar dos cidadãos, bem como do equilíbrio ambiental.

BRASIL. Lei ${ }^{\circ} 11.516$ de 28 de agosto de 2007. Dispõe sobre a criação do Instituto Chico Mendes de Conservação da Biodiversidade.

BRASIL.Decreto n.23.793, de 23 de janeiro de 1934.Aprova o Código Florestal.

BRASIL. Resolução $n^{\circ} 15$ de 03 de setembro de 2004. Resolve realizar uma Campanha Nacional de Sensibilização e Mobilização visando à elaboração e a implementação dos Planos Diretores Participativos 
ABREU, C.C.; CRISOSTIMO, A.L. Aspectos teóricos sobre a tutela jurídica do meio ambiente. Ambiência (Guarapuava), v.3, n.1, p.141-152, 2007.

BRITO, Maria Cecília de. Unidades de Conservação: intenções e resultados. São Paulo: Annablume: FAPESP, 2000. p.19-71.

CASTRO, F.; SIQUEIRA, A.D.; BRONDÍZIO, E.S.; FERREIRA, L.C. Use and misuse of the concepts of tradition and property rights in the conservation of natural resources in the Atlantic forest (Brazil). Ambiente \& Sociedade (Campinas), v.9, n.1, p.23-39, 2006.

FUNDAÇÃO DO MEIO AMBIENTE. (FATMA) Parques. Disponível em < http://www.fatma.sc.gov.br/default/default.asp $>$ Acesso em 30 dez.2007

GODOY, A.M.G. A sugestão sustentável e a concessão das florestas públicas. Revista de Economia Conteporânea (Rio de Janeiro), v.10, n.3, p.631-654, 2006.

INSTITUTO BRASILEIRO DO MEIO AMBIENTE E DOS RECURSOS NATURAIS RENOVAVEIS. (IBAMA) Unidades de Conservação. Disponível em < http://www.ibama.gov.br/> Acesso em 20 dez. 2007.

MALHEIROS, T.F.; Phlippi Jr., A.; Coutinho, S.M.V. Agenda 21 nacional e indicadores de desenvolvimento sustentável: contexto brasileiro. Saúde e Sociedade (São Paulo), v.17, n.1, p.7-20, 2008.

MEDEIROS, R. Evolução das tipologias e categorias de áreas protegidas no Brasil. Ambiente \& Sociedade (Campinas), v.9, n.1, p.41-64, 2008.

MERCADANTE, M. Uma década de debate e negociação: a história da elaboração da Lei do SNUC. In: BENJ A.H. Direito Ambiental das Áreas Protegidas. Rio de Janeiro: Forense Universitária, 2001. 
MILLER, K. R. Evolução do conceito de áreas de proteção oportunidades para o século XXI. In: Anais do I Congresso Brasileiro de Unidades de Conservação. Curitiba: IAP: UNILIVRE: Rede Nacional Pró Unidades de Conservação, Vol. 1: 3-21.1997

PADUA, M.T.J. Unidades de conservação: muito mais do que atos de criação e planos de manejo. In: Unidades de Conservação: Atualidades e Tendências. Curitiba: Fundação O Boticário de Proteção à Natureza, 2002. p. 7 -13.

POMERODE. Plano Diretor Municipal de Pomerode: relatório II/IV. dez 2007.

RÖPER, M. Geografia social e unidades de conservação. Reflexões teóricas e exemplos da Bacia do Alto Rio Paraguai. Geosul (Florianópolis), v.14, n.27, p.45-66, 1999.

RYLANDS, A.B.; BRANDON, K. Unidades de conservação brasileiras. Megadiversidade (Belo Horizonte), v.1, n.1, p.27-35, 2005.

SANTA CATARINA. Projeto de Lei 10.9/2003. Dispõe sobre o critério de distribuição aos Municípios da receita do Imposto sobre Operações Relativas à Circulação de Mercadorias e sobre Prestações de Serviços de Transporte Interestadual e Intermunicipal e de Comunicação - ICMS.

SILVA, J. Unidades de Conservação e Áreas protegidas da Ilha de Santa Catarina. Florianópolis.Insular, 1997.

SOARES,Maria Clara Couto; BENSUSAN, Nurit; FERREIRA NETO, Paulo Sérgio. Entorno de Unidade de Conservação: estudo de experiências com Unidades de Conservação e Proteção Integral. Rio de Janeiro: FUNBIO, 2002.p.13-101.

SOS MATA ATLÂNTICA. Fundação SOS Mata Atlântica/INPE. 2001. Atlas dos remanescentes florestais de Santa Catarina. 
TABARELLI, M.; PINTO, L.P.; SILVA, J.M.C.; HIROTA, M.; BEDE, L. Challenges and opportunities for biodiversity conservation in the Brazilian Atlantic Forest. Conservation Biology, v.19, n.3, p.695-700, 2005.

TEIXEIRA, C. O Desenvolvimento Sustentável em Unidade de Conservação: a "naturalização" do social. Revista Brasileira de Ciências Sociais (), v.20, n.59, 2005.

VALLEJO, L.R. Unidades de conservação: uma discussão teórica à luz dos conceitos de território e de políticas públicas. Geographia (Niterói), v.4, n.8, p.51-72, 2002.

VIBRANS, A. C.; PELLERIN, J. Espaço rural: de espaço de vida a produto de consumo urbano? Observações sobre a bacia do Itajaí. Geosul (Florianópolis), v.19, n.38, p.99-113, 2004.

VITOUSEK, P.M.; MOONEY, H.A.; LUBCHENCO, J.; MELILLO, J.M. Human domination of earth's ecosystems. Science, v.277, n.5325, p.494 - 499, 1997.

WWF-Brasil. Diretrizes para a regulamentação / WWF-Brasil Brasília: 2007.64p. 